\title{
Erişkin çölyaklı hastalarımızın klinik değerlendirilmesi
}

\author{
The clinic evalution of adult celiac diseases
}

Banu Demet COŞKUN ${ }^{1}$, Eylem SEVINÇ², Pınar IPEK ${ }^{3}$, Engin ALTINKAYA ${ }^{1}$, Orhan Kürşat POYRAZOĞLU Ahmet KARAMAN ${ }^{1}$, Hatice KARAMAN ${ }^{4}$

Kayseri Eğitim ve Araştırma Hastanesi, ${ }^{1}$ Gastroenteroloji Kliniği, ${ }^{2}$ Pediatrik Gastroenteroloji Kliniği, ${ }^{3}{ }^{1} c ̧$ Hastalılan Kliniği, ${ }^{4}$ Patoloji Bölümü, Kayseri

\begin{abstract}
Giriş ve Amaç: Çölyak hastalığı tanısı almış erişkin olgularımızın klinik bulgularının, laboratuvar verilerinin ve glutensiz diyete uyumlarının değerlendirilmesi amaçlanmıştır. Gereç ve Yöntem: Bu çalışma, Kayseri Eğitim ve Araştırma Hastanesi, gastroenteroloji bölümünde, Ocak 2011-Aralık 2014 tarihleri arasındaki üç yıllık süreçte izlenen yașları 18-70 yaș arasında değişen, 72'si kadın (\%70,6), 102 çölyak hastasının başvuru şikayetleri, laboratuvar sonuçları, endoskopi bulguları ve duodenum biyopsisi sonuçları retrospektif olarak değerlendirilmiştir. Bulgular: Çalışmaya alınan 102 olgunun

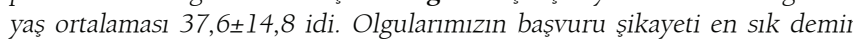
eksikliği anemisi (\%48), ishal (\%40), karın ağrısı- şişkinlik (\%42) iken bunu kilo alım yetersizliği/ kilo kaybı (\%10) ve dispepsi (\%7) izlemektedir. Olgularımızın klinik tiplemesinde 49’u (\%48) klasik, 50'si (\%49,1) atipik, 3’ü $(\% 2,9)$ asemptomatik çölyak hastalığı alt sınıfindaydı. Laboratuvar bulguları içerisinde en sık demir eksikliği anemisi görülürken olguların \%18,6'da karaciğer enzim yüksekliği izlenmiştir. Hastaların üst endoskopilerinde görülen en sık bulgular sirasiyla duodenal ödem, mozaik patern, taraklanma ve pililerde silinme idi. Hastaların \%60'ının diyete uymadıkları tespit edilmiștir. Sonuç: Çölyak hastalığının bașvuru șekillerinin diğer ülkelerde olduğu gibi Türkiye'de de değissik olduğu ve atipik bulgularla başvuran hasta oranının artmış olduğu saptanmıştır. Bu çalışmada çölyak hastalığına bağlı oluşabilecek komplikasyonların önlenmesi için atipik bulgularla gelen hastalara mümkün olduğunca erken tanının konulması ve diyete uyum konusunda hastaların bilinçlendirilmesi gerektiği vurgulanmıştır.
\end{abstract}

Anahtar kelimeler: Çölyak hastalığı, gluten, klinik başvuru
Background and Aims: To investigate the clinical and laboratory effects of a gluten free diet and to determine diet compliance in celiac patients. Materials and Methods: This study was performed in the Department Gastroenterology, Kayseri Training and Research Hospital between January 2011 and December 2014. 102 patients with celiac disease, 72 female (70.6\%), were included in the study. All patients were screened for physical examination findings, laboratory tests, as well as endoscopic and duodenal biopsy results. Results: The mean age of the 102 patients was 37 years $(6 \pm 14,8)$. The most common initial patient complaints were iron deficiency anemia (48\%), diarrhea (40\%), abdominal pain-bloating (42\%), weight loss (\%10) and dyspepsia (7\%), respectively. We observed that the most common laboratory finding was iron deficiency anemia and 18\% had abnormal liver function. The most common finding from patients' upper endoscopy were duodenal edema, mosaic pattern, scalloping and reduction of duodenal pili, respectively. We detected lack of compliance to the gluten free diet in $60 \%$ of celiac disease patients. Conclusion: We found that application form of celiac disease has changed in Turkey as in other countries and an increased proportion of patients present with atypical symptoms. A diagnosis of celiac disease that presents with atypical symptoms should be made as early as possible to prevent complications and educate patients about compliance to a gluten free diet.

Key words: Celiac disease, clinical presentation, gluten

\section{GİRIŞ}

Çölyak hastalığı $(\mathrm{C} H)$ genetik olarak duyarlı kişilerde buğday içerisinde bulunan gliadin veya arpa, çavdar ve yulaf gibi tahılların içerisinde bulanan gliadine eş prolaminlere karşı gelişen immün enteropatidir (1). ÇH) yaygın bir hastalıktır ve birçok çoğrafi bölgelerde popülasyonun 300 veya 100 kişiden birini etkilemektedir. Özellikle 1.derece akrabalarda bu prevalansın \%10-15'lere ulaştığ gözlenmiştir (2). Ülkemizin de arasında bulunduğu ortadoğu ülkelerinde prevalans yaklaşık olarak 1/165 (\%0,6) saptanmıştır (3). Kadın erkek oranı 2:1'dir. ÇH kliniğine göre klasik, atipik, sessiz ve latent olmak üzere 4 gruba ayrilır. Tipik semptomları kronik ishal ve abdominal distansiyondur. Ancak gastrointestinal sistem (GIS) dışı bulgularla da sıklıkla başvurabilmektedirler. Günümüzde buz dağı benzeri tanı almayan hastaların tanı alan hastalardan daha fazla olduğu düşünülmektedir (yaklaşık 1:5-7) $(2,4)$.

ÇH tanısı için pozitif seroloji ile birlikte ince bağırsak biyopsisi altın standartdır. Serolojik olarak bakılan anti-transglutaminaz antikor (anti-tTG) immünglobulin A (IgA) ve immünglobulin $G(\operatorname{Ig} G)$ ve anti-endomisyum antikor IgA (EMA) sensitivitesi \%98, spesifisitesi \%90-99 ile en yüksek tanısal doğruluğa sahip 2 testtir. Tedavi, ömür boyu sürecek glutensiz diyettir. Bu tedaviye sıkı bir şekilde uyulması hastalığın prognozu açısından önemlidir (4). Bu çalışmada Ocak 2011-Aralık 2014 yllları arasında Kayseri Eğitim ve Araştırma Hastanesi, Gastroenteroloji kliniğinde ÇH tanısı koyduğumuz 102 hastanın klinik, laboratuvar bulguları ve izlem sonuçları değerlendirilmiştir. 


\section{GEREC ve YÖNTEM}

Bu çalışmada Kayseri Eğitim ve Araştırma Hastanesi Gastroenteroloji bölümünde, Ocak 2011-Aralık 2014 tarihleri arasındaki üç yıllık süreçte izlenen yaşları 18-70 yaş arasında değişen 72'si kadın $(\% 70,6) 102$ Çölyak hastası; yaş ve cinsiyet dağılımı, başvuru yakınmaları, fizik muayene bulguları, laboratuvar bulguları, tam kan sayımı, biyokimyasal değerleri, ferritin, $B_{12}$ vitamini, folik asit, tiroid fonksiyon testleri, anti-gliadin antikor immunglobulin A (IgA) ve G (IgG), EMA IgA düzeyleri, kemik mineral dansitesi (KMD), endoskopi bulguları, duodenal biyopsi sonuçları, klinik alt tipleri ve ÇH’na eșlik eden diğer hastalıklar açısından değerlendirilmiştir. Istatistiksel analizlerde Pearson korelasyon, Student-t test kullanılmıştır. (SPSS for Windows 21).

\section{BULGULAR}

Çalışmada klinik, serolojik ve ince barsak biyopsisi ile ÇH tanısı konulan 72'si kadın (\%70.6), 30'u (\%29,4) erkek toplam 102 hasta değerlendirilmiştir. Tanı anında ortalama yaş $37,6 \pm 14,8$ yll, kadın ve erkeklerde tanı anında yaş ortalaması $(38,7 \pm 15$ vs $35,7 \pm 14,1, p=0,34)$ olarak bulunmuştur. Çölyaklı hastaların yaş gruplarına göre cinsiyet dağılımı Tablo l'de gösterilmiştir.

Olgularımızın başvuru şikayetleri en sık demir eksikliği anemisi (\%48), ishal (\%40), karın ağnıs-şişkinlik (\%42) iken bunu kilo alım yetersizliği/kilo kaybı (\%10) ve dispepsi (\%7) izlemektedir. Herhangi bir şikayeti olmayan yalnızca aile öyküsü nedeniyle tarama yapılan 3 hastamızda EMA ve/veya AGA IgA pozitifliği saptandı. Bu hastalar hem endoskopik bulgularının hemde incebağırsak histopatolojilerinin normal olması üzerine asemptomatik ÇH olarak adlandırılmışlardır. Bir hastamıza çölyak krizi ile tanı konulmuştur. Olgularımızın ikisinde $(\% 1,9)$ Tip 1 diyabet ile birlikte Hashimato tiroiditi, 1 hastada $(\% 0,9)$ dermatitis herpetiformis, 1 hastada $(\% 0,9)$ Sögren sendromu ve 1 hastada $(\% 0,9)$ vitiligo vardı. ÇH'nın klinik alt tiplerinin görülme sıklığı Tablo 2'de gösterilmiştir.

Laboratuvar bulguları içerisinde en sı anemi görülürken bunların çoğunluğunu demir eksikliği anemisi $(\% 74,5)$ oluşturmaktaydı. Aynı zamanda anemili hastaların \%27,9'inde folik asit eksikliği ve \%21,2'de vitamin $B_{12}$ eksikliği izlenmiştir.

$\begin{array}{lccc}\begin{array}{l}\text { Tablo 1. Çölyaklı hastaların yaş gruplarına ve cinsiyete } \\ \text { göre dağılımı }\end{array} & \text { Kadın (n) } & \text { Erkek (n) } & \text { Total (n) } \\ \text { Yaş grupları } & 8 & 4 & 12 \\ <20 & 14 & 8 & 22 \\ 20-29 & 18 & 8 & 26 \\ 30-39 & 19 & 7 & 26 \\ 40-49 & 13 & 3 & 16 \\ >50 & 72 & 30 & 102 \\ \text { Toplam } & & & \end{array}$

\begin{tabular}{|lc|}
\hline \multicolumn{2}{l}{ Tablo 2. Çölyak hastalığının klinik alt tipleri } \\
\hline & N (\%) \\
\hline Klasik & $49(\% 48)$ \\
Atipik & $50(\% 49,1)$ \\
Asemptomatik & $3(\% 2,9)$
\end{tabular}

Geriye dönük olarak değerlendirdiğimiz hastalarımızın 20'sinin EMA IgA, antigliadin antikor A ve G sonuçlarına ulaşılamadı. 9 hastada tüm serolojik testler negatif iken gerikalan 73 hastanın 50'inde EMA IgA ile birlikte AGA IgA ve/veya IgG pozitifti. 5 hastada yalnızca EMA IgA pozitif idi. Diğer hastalarda EMA IgA negatif iken Anti gliadin A ve/veya G pozitifliği mevcuttu. Hastalarımızın 19'unda $(\% 18,6)$ karaciğer enzim düzeylerinde yükseklik (<2-3 normalin üst sınırı) saptandı. Karaciğer enzim yüksekliği saptanan hastalarımızın hepsinde viral ve otoimmün belirteçler negatif idi. Çölyaklı hastaların laboratuvar ve demografik özellikleri Tablo 3'de gösterilmişstir.

Çalışmamızdaki olguların klinik takip süresi en az 3-4 yıldır. Klinik takiplerde hastalarn diyete uyumu serolojik testler (EMA, AGA IgA and IgG) ve kendisine sorarak izlendi. Bu çalışmada hastaların yarısında diyete uyumu değerlendirebildi ve diyet uyum oranı $\% 40$ olarak saptand. Diyete uyan hastalarda ortalama 1 yıl takip süresince çölyak antikorlarının titrelerinde anlamlı düşme olduğu veya negatifleştiği görüldü.

Kemik mineral dansitesi (KMD) yapabildiğimiz 44 hastamızın 2'i $(\% 4,5)$ normal, 22'sinde (\%50) osteopeni, 6'sında

Tablo 3. Çölyaklı hastaların laboratuvar ve demografik özellikleri

Parametreler

Ortalama \pm Standart sapma

Yaş

$37,6 \pm 14,8$

Cinsiyet (Kadın/Erkek)

$72 / 30$

VKI $\left(\mathrm{kg} / \mathrm{m}^{2}\right)$

$24 \pm 3$

Lökosit $\left(10^{3} / \mu \mathrm{L}\right)$

$6,3 \pm 2,4$

Hemoglobin (gr/dl)

$12(11-13)$

Trombosit $\left(10^{3} / \mu \mathrm{L}\right)$

$310 \pm 110$

AST (IU/L)

$31,2 \pm 18,7$

ALT (IU/L)

$28 \pm 19,8$

GGT (IU/L)

$84,8 \pm 31,5$

ALP (IU/L)

$90,7 \pm 51,5$

Kalsiyum (gr/dl)

9,35 (9-9,6)

Fosfor (gr/dl)

3,5 (3-4)

Total protein ( $\mathrm{gr} / \mathrm{dl})$

$7,2 \pm 1,2$

Albümin (gr/dl)

$3,9 \pm 0,6$

VKI: Vucut kitle indeksi, AST: Aspartat aminotransferaz, ALT: Alanin aminotransferaz, GGT: Gama glutamil transferaz, ALP: Alkalen fosfataz 
$(\% 13,6)$ osteoporoz saptanmıştır. Osteopeni veya osteoporoz saptanan hastalarımızdan hiçbiri postmenapozal dönemde değildi. KMD'si yapılan hastaların \%80'inde serum 25(OH) D düzeyi 20 ng/mL'den düşük tespit edilmiştir. Olgularımızın 15'nin endoskopi sonuçlarına ulaşılamadı. Geri kalan olgularin 10'da mukozal pililerde tam siliklik, 72 hastada duodenal mukozada mozaik tarzında ödemli ve pililerde taraklanma, 5 hastada ise endoskopik bakılarının normal sınırlarda olduğu görüldü (Resim 1). Çölyak tanısı konulan hastaların duodenal biyopsi sonuçları; hastaların 10'u (\%9.8) Marsh-I, 17'si (\%16,6) Marsh-II, 18’i (\%17,6) Marsch-IIIA, 14'ü (\%13,7) Marsh-IIIB, 33'si (\%32,5) Marsh-IIIC ve 10'u (\%9.8) Marsh-IV evresinde idi.

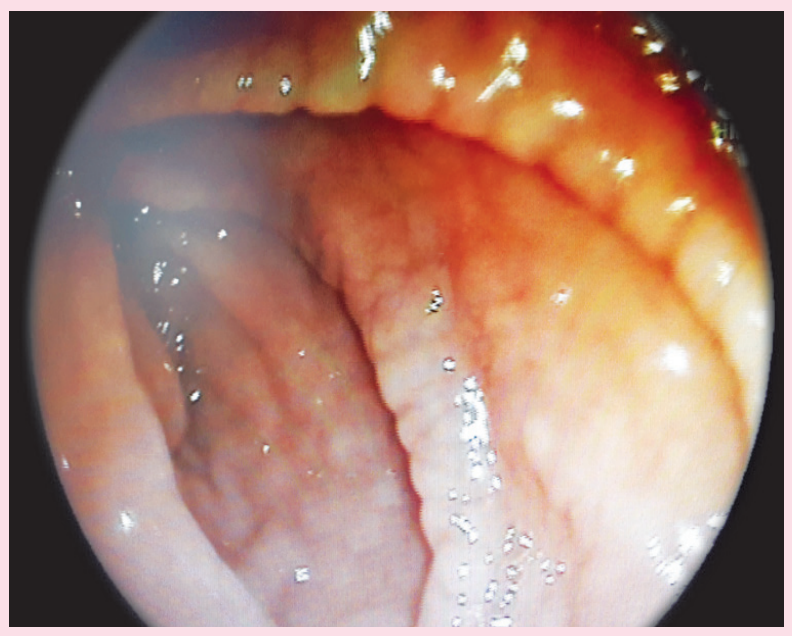

Resim 1. Duodenum mukozasında taraklanma ve ödem

\section{TARTIŞMA}

Çölyak hastalığı ülkemizde de ender olmayan, ancak klinik bulgularının çeşitliliği nedeniyle gözden kaçabilen bir hastalıktır. En bilinen bulguları gastro-intestinal sisteme ait olsa da hastalar atipik bulgularla da başvurabilmektedirler (1). Yapılan çalışmalarda zamanla ishal ile başvuran hastaların prevalansinda azalma olduğu ve atipik semptomlarla tanı konulan ÇH’nın arttığı saptanmıştır (5-7). Nadhem ve arkadaşları; 1980'li yılların başlarında çölyak hastalarının ana başvuru şikayeti \%90 ishal iken günümüzde bu oranın \%40'lara kadar gerilediğini ve Fe eksikliği anemisi, osteopeni gibi atipik başvuru şikayetlerinin sıklığının arttığını bildirmişlerdir (8). Bizim çalışmamızda da olguların \%45'i ishal ile başvururken \%55'inin Fe eksikliği anemisi, osteoporoz, dispepsi gibi atipik bulgularla başvurduğu saptanmıştır. Atipik bulgular içerisinde en sık Fe eksikliği anemisi saptanmıştır.

Ülkemizde çölyak hastalarının başvuru esnasındaki bulgularını araştıran az sayıda çalışma bulunmaktadır. Elsurer ve ark.'nın 60 çölyaklı hastada yaptıkları bir çalışmada en sık semptom ishal, karın şişkinliği ve kilo kaybı olarak saptanmıştır (9). Çoban ve ark. yaptıkları 40 çölyaklı hastada başvuru şikayetlerini sirasıyla diyare ve halsizlik \%80, kilo kaybı \%32,5, karın ağrısı \%30, bulantı ve kusma \%17,5 olarak saptanmıştır (10). Bu çalışmaları değerlendirdiğimiz zaman ülkemizde de son yılda ÇH'nın klinik prezentasyonunun değiştiğini söyleyebiliriz. Bu durum hastalığın farkındalığının artması ile taramanın yaygınlaşmasına bağlanabilir.

Tedavi edilmeyen ÇH'da emilim bozukluğu sonucu demir eksikliğinin yanı sıra folik asit, vitamin $\mathrm{B}_{12}$, vitamin $\mathrm{B}_{6}$, bakır ve çinko eksiklikleri de tespit edilmiştir. ÇH'da vakaların \%12'sinde vitamin $B_{12}$ eksikliği saptanmıştır $(11,12)$. Bizim çalışmamızda da vakaların \%74'ünde demir, \%27,9'inde folik asit eksikliği ve \%21,2'de vitamin $\mathrm{B}_{12}$ eksikliği saptanmıştır. $\mathrm{Bu}$ durumda ÇH tanısı koyduğumuz hastaları aynı zamanda serum $B_{12}$ ve folik asit düzeylerinin bakılması ve eksikliğin yerine konulması gerektiğini göstermektedir.

Çölyak hastaları kalsiyum ve yağda eriyen vitaminlerden D vitamini emilim bozukluğuna bağlı olarak rikets, osteopeni ve osteoporoz ile karşımıza gelebilir (13). Hjelle ve arkadaşlarının 2014 yılında yaptıkları kesitsel çalışmada gerek yeni tanı almış gerekse takipli ÇH olan olgularda KMD ölçümünün önemine vurgu yapmışlar (14). Bu çalışmada biz hastaların \%43'ünün KMD ve vitamin D düzeylerine ulaşabildik. Bu hastaların \%80'inde $25(\mathrm{OH}) \mathrm{D}$ düzeyleri düşük saptanmış olup KMD sonuçları; sirasıly hastaların 2'sinde $(\% 4,5)$ normal, 22'sinde (\%50) osteopeni, 16'sinda (\%13,6) osteoporoz şeklinde idi.

ÇH'ı olan kişilerde genel popülasyona göre 10 kat fazla otoimmün hastalıklar oluşur. Bu sık görülebilen otoimmün hastalıklar sirasılla Tip 1 diabetes mellitus (\%5-6), tiroid hastalıkları (\%5), Sjögren sendromu, Addison hastalığı, otoimmün hepatit, kardiyomyopati ve nörolojik hastalıklardır. Bir hastada hem ÇH hemde otoimmün hastalık gelişir ise genellikle ÇH sessiz olup genellikle ilk tanı otoimmün hastalık olmaktadır. Bu nedenle bu hastalıkları olanların ÇH açısından da taranması önerilmektedir (1,2). Bizim çalışmamızda da olgularımızın ikisinde $(\% 1,9)$ Tip 1 diabetes mellitus ile birlikte Hashimato tiroiditi, 1 hastada $(\% 0,9)$ Sögren sendromu, 1 hastada $(\% 0,9)$ dermatitis herpetiformis ve 1 hastada $(\% 0,9)$ vitiligo vardı. Sjögren sendromu olan hastamızın aynı zamanda 1. derece akrabasında da ÇH öyküsü mevcuttu. Bu durum ÇH'nın etyolojisinde genetiğin güçlü bir rolü olduğu görüşünü desteklemektedir.

ÇH'nın sistemik tutulumlarından bir diğeri de karaciğerdir. Bu tutulumda en sik izole karaciğer enzimlerinde yükseklik görülmektedir ve glutensiz diyet ile çoğu hastada normale döndügü izlenmiştir. ÇH'da anormal karaciğer enzim yüksekliği prevalansını Bardella ve arkadaşları \%42 (15), Novacek ve arkadaşları \%40 (16), Castillo ve arkadaşları \%40.6 olarak 
saptamıştır (17). Tersine nedeni açıklanamayan karaciğer enzim yüksekliğinde ÇH’nın prevalansı \%9 olarak saptanmıştır (16). Aynı zamanda ÇH'ı otoimmün hepatit, primer biliyer siroz ve primer sklerozan kolanjit gibi otoimmün karaciğer hastalıklarıyla da birlikte olabilir. Bizim çalışmamızda hastaların \%18,6'sında karaciğer enzim yüksekliği saptanmıştır. Glutensiz diyetle hastaların yarısında karaciğer enzimlerinde düşme eğilimi gözlenmiştir. Diğer otoimmün hastalıklarla birliktelik izlenmemiştir.

ÇH'nın tedavisi yaşam boyu glutensiz diyettir. Ancak glutensiz diyet yorgunluk, yaşam kalitesinde azalma ve depresyon

\section{KAYNAKLAR}

1. Rubio-Tapia A, Hill ID, Kelly CP, et al. ACG Clinical Guidelines: Diagnosis and Management of Celiac Disease. Am J Gastroenterol 2013; 108:656-676

2. Bai JC, Fried M, Corazza GR, et al. World Gastroenterology Organisation global guidelines on celiac disease. J Clin Gastroenterol 2013;47:121-6.

3. Naiyana G, Hugh JF, Alan T. Celiac disease: Prevalence, diagnosis, pathogenesis and treatment. World J Gastroenterol 2012;18:6036-59.

4. Husby S, Koletzko S, Korponay-Szabo IR, et al. European Society for Pediatric Gastroenterology, Hepatology, and Nutrition Guidelines for the Diagnosis of Coeliac Disease. JPGN 2012; 54:136-60.

5. Murray JA, Van Dyke C, Plevak MF, et al. Trends in the identification and clinical features of celiac disease in a North American community, 1950-2001. Clin Gastroenterol Hepatol 2003;1:19-27.

6. Lo W, Sano K, Lebwohl B, et al. Changing presentation of adult celiac disease. Dig Dis Sci 2003;48:395-8.

7. Rampertab SD, Pooran N, Brar P, et al. Trends in the presentation of celiac disease. Am J Med 2006;119:355.e9-14.

8. Nadhem ON, Azeez G, Smalligan RD, Urban S. Review and practice guidelines of celiac disease in 2014. Postgrad Med 2015;127:259-65.

9. Elsurer R, Tatar G, Simşek H, et al. Celiac disease in the Turkish Population. Dig Dis Sci 2005; 136-142.

10. Çoban \$̧, Palabıyıklıŏlu M, Örmeci N. Gluten sensitif enteropatili hastalarımızın değerlendirilmesi. Türkiye Klinikleri J of Gastroenterohepatol $2003 ; 14: 147-50$. gibi problemlere yol açabildiğinden diyete uyum zorlaşmaktadır. Yapılan çalışmalarda yetişkin ÇH'da kullanılan metoda göre glutensiz diyete uyum oranı \%36 ile \%96 arasında rapor edilmiştir. Biz çalışmamızda diyete uyum oranını \%40 olarak saptadık.

Sonuç olarak; Çölyak hastalı̆̆ı olan olgularımızı değerlendirerek yaptığımız bu çalışmada; Çölyak hastalığına bağlı oluşabilecek komplikasyonların önlenmesi için atipik bulgularla gelen hastalara mümkün olduğunca erken tanının konulması ve diyete uyum konusunda hastaların bilinçlendirilmesi gerektiğini vurgulamak istedik.

11. Tikkakoski S, Savilahti E, Kolho KL. Undiagnosed coeliac disease and nutritional deficiencies in adults screened in primary health care. Scand J Gastroenterol 2007;42:60-5.

12. Haapalahti M, Kulmala P, Karttunen TJ, et al. Nutritional status in adolescents and young adults with screen-detected celiac disease. J Pediatr Gastroenterol Nutr 2005;40:566-70.

13. Meyer D, Stavropolous S, Diamond B, et al. Osteoporosis in a North American adult population with celiac disease. Am J Gastroenterol 2001;96:112-9.

14. Hjelle AM, Apalset E, Mielnik P, et al. Celiac disease and risk of fracture in adults--a review. Osteoporos Int 2014;25:1667-76.

15. Bardella MT, Vecchi M, Conte D, et al. Chronic unexplained hypertransaminasemia may be caused by occult celiac disease. Hepatology 1999;29:654-7.

16. Novacek G, Miehsler W, Wrba F, et al. Prevalence and clinical importance of hypertransaminasaemia in coeliac disease. Eur J Gastroenterol Hepatol 1999;11:283-8.

17. Castillo NE, Vanga RR, Theethira TG, et al. Prevalence of abnormal liver function tests in celiac disease and the effect of a gluten-free diet in the US population. Am J Gastroenterol 2015;110:1216-22.

18. Nejad MR, Alavian S. Celiac disease and abnormal liver function test. Int J Prev Med 2012;3:745-6.

19. Hall NJ, Rubin G, Charnock A. Systematic review: adherence to a gluten-free diet in adult patients with coeliac disease. Aliment Pharmacol Ther 2009;30:315-30. 